\title{
Preliminary studies on the fate of the flavonol glycoside rutin in the forestomachs of sheep
}

\author{
R. Parrinder ${ }^{1}$, J. L. Atkinson ${ }^{1}$, J. M. Dawson ${ }^{1}$, P. J. Buttery ${ }^{1}$ and M. Gill ${ }^{2}$ \\ 'Department of Applied Biochemistry and Food Science, University of Nottingham School of Agriculture, \\ Sutton Bonington, Loughborough LE12 5RD \\ ${ }^{2}$ Natural Resources Institute, Central Avenue, Chatham Maritime, Kent ME4 4TB
}

\section{Introduction}

Polyphenolics are a common group of antinutritional factors which occur in many browse plants found in the tropics and have been implicated in the poor performance of ruminants. These effects could occur in the rumen or, if they escape degradation, in the intestine or animal tissues. Most of the published reports have concentrated on examination of the effect of feeding plants containing antinutritional factors or, in a few cases, the effects of extracts containing a mixture of supposedly antinutritional compounds. We have adopted an alternative approach of investigating the metabolism of individual polyphenolic compounds in ruminants, with the aim of assessing the potential importance of specific compounds rather than that of broad groups. For our initial studies the flavonol glycoside rutin was chosen since it has been reported to reach concentrations of 30 to $50 \mathrm{~g} / \mathrm{kg}$ dry weight in some plant materials (Swain, 1979). Chemical attributes of rutin which might influence its metabolism were initially studied, followed by investigations of its catabolism in vivo.

Polyphenolics from oak leaves have also been implicated in the inhibition of urease activity in the rumen (Makkar, Singh and Dowra, 1988) and we have detected appreciable quantities (1 to $3 \mathrm{mg} / \mathrm{g}$ dry weight) of rutin in several species of oak leaves. However in vitro incubation of 0.8 and $1.6 \mathrm{mg}$ rutin per $\mathrm{ml}$ rumen liquor at $39^{\circ} \mathrm{C}$ for $3 \mathrm{~h}$ had no effect on the rate of ammonia release by urease, as measured by the phenol hypochlorite reaction.

\section{Material and methods}

Rutin was obtained from Aldrich Chemical Co. Ltd (Gillingham, Dorest). Analysis of rutin was carried out using reverse-phase HPLC with a diode-array detector. Samples were eluted from a $250 \times 4.6 \mathrm{~mm}$ column (C18 ODS Hypersil) with an acetic acid/ methanol linear gradient; starting with a $2 \%$ glacial acetic acid $/ 98 \%$ water mixture changing to $100 \%$ methanol over a 20-min period. Absorption was measured over 300 to $360 \mathrm{~nm}$ range, at $5-\mathrm{nm}$ intervals, routinely to assess the purity of the rutin peak. Concentrations were assessed by measuring the peak area at $\max (355 \mathrm{~nm})$.

\section{Experiment 1}

Rutin's stability at pHs likely to be met in the ruminant intestinal tract was investigated; rumen (6.0 to 7.0$)$, duodenum ( 8.0 to 9.0 ) and abomasum (2.0 to 3.0$)$.

\section{Experiment 2}

Sufficient rutin was introduced via a fistula, into the rumen of sheep given a pelleted grass-meal diet, to produce an estimated rumen concentration of $75 \mu \mathrm{g} / \mathrm{ml}$, well above the lower limit of detection (10 $\mathrm{ng} / \mathrm{ml}$ rumen liquor). Strained and unstrained rumen samples taken $30 \mathrm{~min}$ after rutin administration, were analysed, both before and after extraction with $50 \%$ aqueous acetone.

\section{Experiment 3}

To examine the extent of metabolism, rutin $(1 \mathrm{mg} /$ $\mathrm{ml}$ ) was incubated with rumen liquor for $2 \mathrm{~h}$ at $39^{\circ} \mathrm{C}$ (Figure 2).

\section{Results}

Experiment 1

The compound was found to be stable at neutral $\mathrm{pH}$ (Figure 1) and no degradation was detected with prolonged incubation $(24 \mathrm{~h})$ at $39^{\circ} \mathrm{C}$. At alkaline $\mathrm{pH}$ the material was unstable; at acidic $\mathrm{pH}$ there was a tendency for the material to precipitate from solution as well as to be degraded. Rutin bound rapidly to grass meal, polyphenolics characteristically binding 


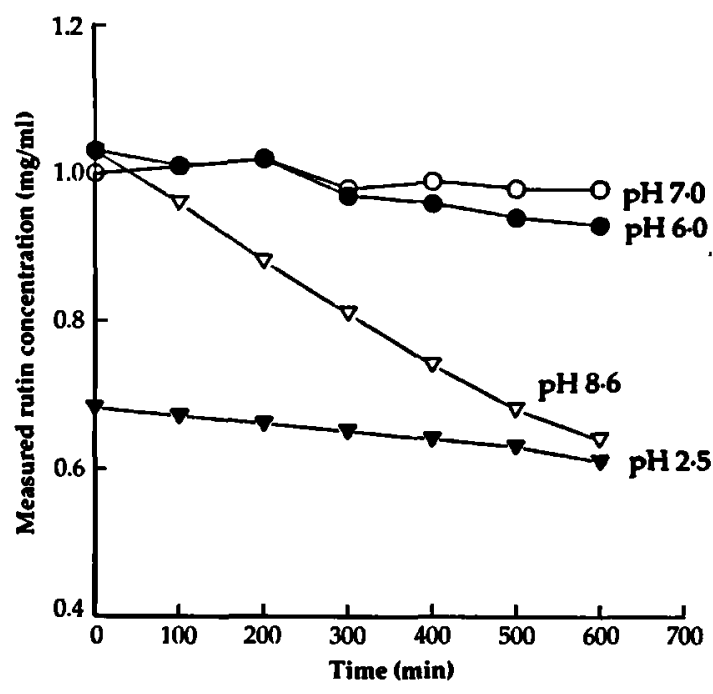

Figure 1 Stability of rutin solution $(1 \mathrm{~g} / \mathrm{l})$ at different $\mathrm{pHs}$ in vitro.

to protein and carbohydrates (Makkar, Singh and Dowra, 1987). Rutin also bound to strained and whole samples of rumen liquor. This binding could be readily and quantitatively reversed by treatment with $50 \%(\mathrm{v} / \mathrm{v})$ aqueous acetone. Binding to whole rumen liquor was more pronounced than binding to strained rumen liquor (see Figure 2).

\section{Experiment 2}

No rutin was detected. This implies it was either degraded in the rumen, absorbed or flowed out of the rumen into the intestines, however no rutin was detected in samples of duodenal digesta taken every $\mathbf{3 h}$ for $\mathbf{4 8} \mathrm{h}$ after the initial administration.

\section{Experiment 3}

From the acetone extraction fraction (to account for binding) it appeared that approximately a quarter of the rutin was catabolized during the incubations.

\section{Discussion}

Rutin administered to the rumen in a free form rapidly disappeared from the rumen liquor, but was not detected in duodenal digesta. Rapid metabolism by the rumen micro-organisms is likely, but degradation products have not been identified. Degradation of rutin by gut micro-organisms has been indicated in other species: germ free rats given rutin in their diet excreted the compound unchanged in their urine but in conventional rats only catabolic products, described as phenolic acids of rutin, were detected (Griffiths and Barrow, 1972).
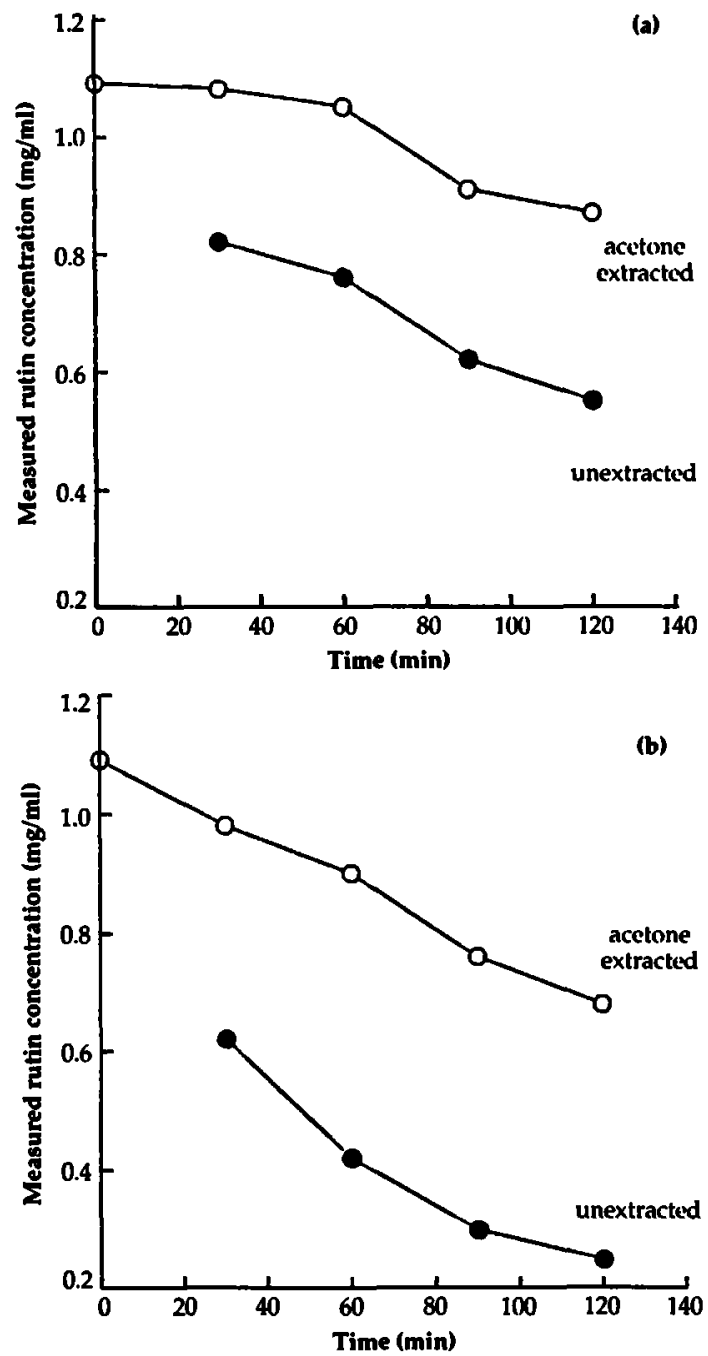

Figure 2 Effect of rutin ( $1 \mathrm{mg} / \mathrm{ml}$ ) binding to (a) strained rumen fluid and (b) whole rumen fluid extraction with $50 \%$ acetone.

\section{References}

Griffiths, L. A. and Barrow, A. 1972. Metabolism of flavoured compounds in germ-free rats. Biochemical Journal 130: 1161-1162.

Makkar, H. P. S., Singh, B. and Dawra, R. K. 1987. Tanninnutrient interactions: a review. Intermational Journal of Animal Science 2: 127.

Makkar, H. P. S., Singh, B. and Dawra, R. K. 1988. Effect of tannin-rich leaves of oak ( $Q$. incaria) on various microbial enzyme activities of the bovine rumen. British Jourmal of Nutrition 60: 287-296.

Swain, T. 1979. In Herbiwores: their interaction with secondary plant metabolics (ed. G. A. Rosenthal and D. H. Janzen). New York, Academic Press. 